\title{
K podobnostim in različnostim slovenskega in madžarskega pregibanja
}

\author{
Vlado Nartnik
}

Cobiss: 1.02

Slovenščina in madžarščina sta sosedna jezika z zelo različnim pregibanjem. V glagolskem pregibanju je madžarska posebnost zlasti razlikovanje nedoločne in določne sprege. Ker madžarščina nima posebne oblike za rodilnik, jo nadomešča s svojilno sprego samostalnih skladov, slovenskim predložnim sklonom pa ustrezajo po trije snopi prostih sklonov in priložnih skladov.

Ključne besede: slovenščina, madžarščina, glagoli nedovršnega in dovršnega vida, nedoločna in določna sprega, glagola bitja in imetja, svojilna sprega samostalnih skladov, prosti skloni in priložni skladi, ciljni, krajevni in startni snopi

\section{Similarities and differences between Slovenian and Hungarian inflection}

Slovenian and Hungarian are neighboring languages with very different inflection. In verbal conjugation a special feature of Hungarian is the distinction between indefinite and definite conjugations. Because Hungarian does not have a special form for the genitive, this is substituted for by a possessive inflection of substantival constructions, whereas the Slovenian locative and instrumental cases correspond to simple cases and constructions with postpositions with a three-way orientational distinction.

Keywords: Slovenian, Hungarian, imperfective and perfective verbs, indefinite and definite conjugation, verbs of being and having, possessive inflection of substantival constructions, simple cases and constructions with postpositions, allative, essive, and ablative sets

\section{$1 \quad$ Uvod}

Slovenščina in madžarščina veljata za daljni potomki indouralščine (Erhart 1982: 24). Ta se je nekdaj govorila med Uralom in Pontom ter se postopno razvejila v bolj južno indoevropščino in bolj severno uralščino (Kortlandt 2002: 217), v nadaljnjih tisočletjih pa je iz baltoslovanske veje indoevropščine med drugim izšla slovenščina podobno kakor iz ugrofinske veje uralščine madžarščina. V dolgi ločenosti je tudi vzrok za veliko različnost slovenščine in madžarščine, čeprav sta se celo minulo tisočletje razvijali v novi, alpsko-panonski soseščini. 


\section{- $\quad 2.1 \quad$ Osnovna sprega}

[स Različnost se kaže že v oblikoglasju, saj je naglašanje bolj raznotero v slovenščiN ni, medtem ko pregibanje pestri madžarska težnja po harmoniji samoglasnikov v - okviru posameznih besed (Skalička 1975: 25). V oblikoskladju sicer oba jezika त poznata klitične in tonične oblike spregalnoosebnih zaimkov, s tem da so prve najprej zvalno-nazivno ničelne (Nartnik 2006: 93). Zvalno-nazivna ničelnost klitičnih oblik namreč dopušča pregibanje samih glagolov, tu pa mimo naglasne in glasovne raznoterosti posebej izstopa slovensko vezanje glagolske sprege z nedovršnim in dovršnim vidom v ednini, dvojini in množini (Bezlaj 2003: 703) nasproti madžarskemu vezanju glagolske sprege $\mathrm{z}$ nedoločno in določno prehodnostjo $\mathrm{v}$ ednini in množini (Allières 2000: 112):

\begin{tabular}{|c|c|c|c|c|c|c|c|c|}
\hline & & nedov & & dov & & nedol & & dol \\
\hline$\varnothing$ & $\rightarrow$ & dajem & - & dam & $\varnothing$ & $\rightarrow$ adok & - & adom \\
\hline$\varnothing$ & $\rightarrow$ & daješ & - & daš & $\varnothing$ & $\rightarrow$ adsz & - & adod \\
\hline$\varnothing$ & $\rightarrow$ & daje & - & $\mathrm{da}$ & $\varnothing$ & $\rightarrow$ ad & - & adja \\
\hline$\varnothing$ & $\rightarrow$ & dajeva & - & dava & & & & \\
\hline$\varnothing$ & $\rightarrow$ & dajeta & - & dasta & & & & \\
\hline$\varnothing$ & $\rightarrow$ & dajeta & - & dasta & & & & \\
\hline$\varnothing$ & $\rightarrow$ & dajemo & - & damo & $\varnothing$ & $\rightarrow$ adunk & - & adjuk \\
\hline$\varnothing$ & $\rightarrow$ & dajete & - & daste & $\varnothing$ & $\rightarrow$ adtok & - & adjátok \\
\hline$\varnothing$ & $\rightarrow$ & dajejo & - & dajo & $\varnothing$ & $\rightarrow$ adnak & - & adják \\
\hline
\end{tabular}

Nasproti slovenskemu razlikovanju tožilnika moškega in ženskega ter srednjega spola tipa $g a-j o-g a$ v ednini vrh tega stoji madžarska dvotirnost glagolske sprege lát - látja (Bernjak 2004: 194), ki kaže na nedoločnost tožilnika engem - minket za prvo in teged - titeket za drugo ter določnost tožilnika öt - öket za tretjo osebo ednine oziroma množine v iskalnih vprašanjih (Naumenko-Papp 1982: 249):

Kdo me vidi dajati?

Kdo te vidi dajati?

Kdo ga ... vidi dajati?

Kdo naju vidi dajati?

Kdo vaju vidi dajati?

Kdo jiju vidi dajati?

Kdo nas vidi dajati?

Kdo vas vidi dajati?

Kdo jih vidi dajati?
Ki lát engem adni?

Ki lát téged adni?

Ki látja őt adni?

Ki lát minket adni?

Ki lát titeket adni?

Ki látja őket adni?

\subsection{Povratna sprega}

Vmesno varianto glagolske sprege pa kaže potlačena povratnost v povzemalnih vprašanjih (Mukič 1997: 210, 241): 
Mene je videti?

Tebe je videti?

Njega ... je videti?

Naju je videti?

Vaju je videti?

Njiju je videti?

Nas je videti?

Vas je videti?

Njih je videti?
Én látszom?

Te látszol?

Ő látszik?

Mi látszunk?

Ti látszotok?

Ök látszanak?

Pri izrecni povratnosti je spet določen tožilnik vseh treh oseb ednine oziroma množine (Tutek 2010: 736):

Jaz se vidim?

Ti se vidiš?

On ... se vidi?

Midva ... se vidiva?

Vidva ... se vidita?

Onadva ... se vidita?

Mi ... se vidimo?

Vi ... se vidite?

Oni ... se vidijo?
Én látom magam?

Te látod magad?

Ö látja magát?

Mi látjuk magunkat?

Ti látjátok magatokat?

Ők látják magukat?

Nasproti slovenskemu razlikovanju spregalnega nazivnika moškega in ženskega ter srednjega spola tipa on - ona - ono v ednini, midva - medve - midva, vidva - vedve - vidva in onadva - onedve - onadva $\mathrm{v}$ dvojini ter $m i-m e-m i, v i-v e-v i$ in oni - one - ona $\mathrm{v}$ množini stoji zdaj daljnosežno razlikovanje povratnega tožilnika $\mathrm{v}$ madžarščini.

\subsection{Osnovni skloni}

$\mathrm{V}$ osnovnih sklonih iskalnih zaimkov od nazivnika do dajalnika se namreč jezika razhajata tako, da se $\mathrm{v}$ slovenščini opisuje manjkajoča množina tipa ... vse, v madžarščini pa manjkajoči rodilnik (Naumenko-Papp 1982: 207; 226):

$\begin{array}{lllll} & \text { osebe } & \text { stvari } & \text { osebe } & \text { stvari } \\ \text { N ed } & \text { kdo } & \text { kaj } & \text { ki } & \text { mi } \\ \text { N mn } & \text { kdo vse } & \text { kaj vse } & \text { kik } & \text { mik } \\ \text { Ted } & \text { koga } & \text { kaj } & \text { kit } & \text { mit } \\ \text { Tmn } & \text { koga vse } & \text { kaj vse } & \text { kiket } & \text { miket } \\ \text { Red } & \text { koga } & \text { česa } & & \\ \text { Rmn } & \text { koga vse } & \text { česa vse } & & \\ \text { Ded } & \text { komu } & \text { čemu } & \text { kinek } & \text { minek } \\ \text { Dmn } & \text { komu vse } & \text { čemu vse } & \text { kiknek } & \text { miknek }\end{array}$




\section{- $\quad 3.2 \quad$ Vezni glagol biti}

[स Primer slovenskega opisovanja kazalne množine ezek - azok-amazok ob toničnih

N oblikah spregalnoosebnih zaimkov $m i-t i-o ̋ k$ je sicer nedopuščanje ničelnih oblik

- tretje osebe veznega glagola ø, značilnih za madžarščino (Mukič 1997: 28 in 255):

To sem jaz

Tisto si ti

- Ono je on ...

Ez én vagyok

Az te vagy

To sva midva ...

Amaz ő ø

Tisto sta vidva ...

Ono sta onadva ...

- To smo mi ...

Tisto ste vi ...

Ezek mi vagyunk

Ono so oni ...

Azok ti vagytok

Amazok ők ø

- Pred ničelno vezjo $ø$ se predhodno vzpostavi še svojilna sprega samostalnih imen

- (Naumenko-Papp 1982: 278):

त To je moj maček

$-\quad$ Tisto je tvoj maček

ㄱ Ono je njegov ... maček

To je najin maček

Tisto je vajin maček

Ono je njijin maček

To je naš maček

Tisto je vaš maček

Ono je njihov maček

To so moji mački

Tisto so tvoji mački

Ono so njegovi ... mački

To so najini mački

Tisto so vajini mački

Ono so njijini mački

To so naši mački

Tisto so vaši mački

Ono so njihovi mački
Ez az én kandúrom ø

$\mathrm{Az}$ a te kandúrod ø

Amaz az ő kandúrja ø

Ez a mi kandúrunk ø

Az a ti kandúrotok ø

Amaz az ő kandúrjuk ø

Ezek az én kandúrjaim ø

Azok a te kandúrjaid ø

Amazok az ő kandúrjai ø

Ezek a mi kandúrjaink ø

Azok a ti kandúrjaitok ø

Amazok az ő kandúrjaik ø

Medtem ko se v navezavi na sprego v slovenščini za veznim glagolom je javlja razlikovanje moške in ženske svojilnosti tipa njegov - njen, se v madžarščini pred ničelno vezjo $\varnothing$ vzpostavi dvodelna svojilnost, razvidna iz vzporednosti tipa az én kandúrom $\rightarrow$ az enyém in a mi kandúrunk $\rightarrow$ a mienk (Mukič 1997: 77):

Ta maček je moj

Tisti maček je tvoj
Ez a kandúr az enyém ø

Az a kandúr a tied ø 
Oni maček je njegov ...

Amaz a kandúr az övé ø

Ta maček je najin

Tisti maček je vajin

Oni maček je njijin

Ta maček je naš

Tisti maček je vaš

Oni maček je njihov

Ez a kandúr a mienk ø

Az a kandúr a tietek ø

Amaz a kandúr az övék ø

Ti mački so moji

Tisti mački so tvoji

Oni mački so njegovi ...

Ti mački so najini

Tisti mački so vajini

Oni mačke so njijini

Ti mački so naši

Tisti mački so vaši

Oni mačke so njihovi

Ezek a kandúrok az enyéim ø

Azok a kandúrok a tieid ø

Amazok a kandúrok az övéi ø

Ezek a kandúrok a mieink ø

Azok a kandúrok a tieitek ø

Amazok a kandúrok az övéik ø

\subsection{Sevni glagol biti}

Nadaljnji primer dvodelne svojilnosti je obrat dajalne pripone -nek iskalnoosebnega zaimka kinek v dajalno predpono nek-spregalnoosebnih zaimkov nekem ... nekünk ... $\mathrm{v}$ vlogi imetnikov pred imetno rabljenim glagolom sevnega bivanja van (Bernjak 2004: 171) ter nedoločnim nazivnikom s svojilnimi priponami egy kandúrom ... egy kandúrunk ... v vlogi imetij:

Jaz imam mačka

Ti imaš mačka

On ... ima mačka

Midva ... imava mačka

Vidva ... imata mačka

Onadva ... imata mačka

Mi ... imamo mačka

Vi ... imate mačka

Oni ... imajo mačka

Jaz imam mačke

Ti imaš mačke

On ... ima mačke

Midva ... imava mačke

Vidva ... imata mačke

Onadva ... imata mačke

Mi ... imamo mačke

$\mathrm{Vi}$... imate mačke

Oni ... imajo mačke
Nekem van egy kandúrom

Neked van egy kandúrod

Neki van egy kandúrja

Nekünk van egy kandúrunk

Nektek van egy kandúrotok

Nekik van egy kandúrjuk

Nekem vannak kandúrjaim

Neked vannak kandúrjaid

Neki vannak kandúrjai
Nekünk vannak kandúrjaink

Nektek vannak kandúrjaitok

Nekik vannak kandúrjaik 
- Dodatni korak pomeni ciljna pozaimitev imetja rá - rájuk pred samostalnikom po-

프 trebe v obliki nazivnika s svojilnimi priponami szükségem ... szükségünk ....

- Jaz ga moram imeti

ㅈ Ti ga moraš imeti

- On ... ga mora imeti

is Midva ... ga morava imeti

- Vidva ... ga morata imeti

- Onadva ... ga morata imeti

$<\quad \mathrm{Mi}$... ga moramo imeti

Z Vi ... ga morate imeti

Oni ... ga morajo imeti

N Jaz jih moram imeti

$>$ Ti jih moraš imeti

$\checkmark \quad$ On ... jih mora imeti

- Midva ... jih moramo imeti

(2) Vidva ... jih morate imeti

त Onadva ... jih morajo imeti

- Mi ... jih moramo imeti

$\because \quad$ Vi ... jih morate imeti

Oni ... jih morajo imeti
Nekem van rá szükségem

Neked van rá szükséged

Neki van rá szüksége

Nekünk van rá szükségünk

Nektek van rá szükségetek

Nekik van rá szükségük

Nekem van rájuk szükségem

Neked van rájuk szükséged

Neki van rájuk szüksége

Nekünk van rájuk szükségünk

Nektek van rájuk szükségetek

Nekik van rájuk szükségük

Pri zanikanju imetno rabljenega glagola sevnega bivanja nincs se nato vzpostavi dajalnik spregalnoosebnih zaimkov v vlogi imetnikov v obeh jezikih (Nartnik 1982: 355):

Meni ga ni treba imeti

Tebi ga ni treba imeti

Njemu ... ga ni treba imeti

Nama ga ni treba imeti

Vama ga ni treba imeti

Njima ga ni treba imeti

Nam ga ni treba imeti

Vam ga ni treba imeti

Njim ga ni treba imeti

Meni jih ni treba imeti

Tebi jih ni treba imeti

Njemu ... jih ni treba imeti

Nama jih ni treba imeti

Vama jih ni treba imeti

Njima jih ni treba imeti

Nam jih ni treba imeti

Vam jih ni treba imeti
Nekem nincs rá szükségem

Neked nincs rá szükséged

Neki nincs rá szüksége

Nekünk nincs rá szükségünk

Nektek nincs rá szükségetek

Nekik nincs rá szüksége

Nekem nincs rájuk szükségem

Neked nincs rájuk szükséged

Neki nincs rájuk szüksége

Nekünk nincs rájuk szükségünk

Nektek nincs rájuk szükségetek

Nekik nincs rájuk szükségük 


\subsection{Svojilni skladi}

Primer madžarskega opisovanja manjkajočega rodilnika je obratnosvojilna veriga soseda kot prvega imetnika, njegove mačke kot imetja prve stopnje in druge imetnice ter njenega mačka kot imetja druge stopnje (Naumenko-Papp 1982: 274):

To je maček mačke mojega soseda

To sta mačka mačk mojih sosedov

To so mački mačk mojih sosedov

Ez az én szomszédom macskájának a kandúrja ø

Ezek az én szomszédaim macskáinak a kandúrjai ø

Obratnosvojilne verige se navadno krčijo v svojilne sklade, ki ustrezajo slovenskemu nihanju med zvezami s svojilnim pridevnikom in svojilnim rodilnikom (Bernjak 2004: 168):

To je sosedov maček

To sta sosedova mačka

Ez a szomszéd kandúrja ø

To so sosedovi mački

Ezek a szomszéd kandúrjai ø

To je maček sosedov

Ez a szomszédok kandúrja ø

To sta mačka sosedov

To so mački sosedov

Ezek a szomszédok kandúrjai ø

\subsection{Ciljni skloni in skladi}

V nasprotju s slovenščino pa madžarskemu dajalniku namesto predložnih sledijo prosti skloni in priložni skladi (Naumenko-Papp 1982: 214; 230). V pretežno ciljnem snopu prostih sklonov se pripone spet obračajo v predpone svojilne sprege, primerljive z izpredložnim tožilnikom ednine (Naumenko-Papp 1982: 282):

$\begin{array}{lllll} & \text { osebe } & \text { stvari } & \text { osebe } & \text { stvari } \\ \text { Ted } & \text { v koga } & \text { v kaj } & \begin{array}{l}\text { kibe } \\ \text { belém }\end{array} & \text { mibe } \\ \text { Ted } & \text { vame } & & & \\ \text { Tdv } & \text { v naju } & & \text { belénk } & \\ \text { Tmn } & \text { v nas } & & \text { kire } & \text { mire } \\ \text { Ted } & \text { na koga } & \text { na kaj } & \text { rám } & \\ \text { Ted } & \text { name } & & \text { rame } & \\ \text { Tdv } & \text { na naju } & & & \\ \text { Tmn } & \text { na nas } & & \text { ránk } & \end{array}$

V priložnih skladih se izglasna pripadnost snopu še bolj jasno prenese na priloge, ki so tokrat sami primerljivi predvsem z izpredložnim tožilnikom ednine (Deme 1984: 174): 


\begin{tabular}{|c|c|c|c|c|}
\hline$=$ & osebe & stvari & osebe & stvari \\
\hline Ted & pred koga & pred kaj & ki elé & mi elé \\
\hline Ted & predme & & elém & \\
\hline $\mathrm{Tdv}$ & pred naju & & & \\
\hline Tmn & pred nas & & elénk & \\
\hline Ted & nad koga & nad kaj & ki fölé & mi fölé \\
\hline Ted & nadme & & fölém & \\
\hline $\mathrm{Tdv}$ & nad naju & & & \\
\hline Tmn & nad nas & & fölénk & \\
\hline Ted & za koga & za kaj & ki mögé & mi mögé \\
\hline Ted & zame & & mögém & \\
\hline $\mathrm{Tdv}$ & za naju & & & \\
\hline Tmn & za nas & & mögénk & \\
\hline Ted & pod koga & pod kaj & ki alá & mi alá \\
\hline Ted & podme & & alám & \\
\hline $\mathrm{Tdv}$ & pod naju & & & \\
\hline Tmn & pod nas & & alánk & \\
\hline Ted & med koga vse & med kaj vse & kik közé & mik közé \\
\hline Ted & medme in tebe & & közém és közéd & \\
\hline $\mathrm{Tdv}$ & med naju & & & \\
\hline Tmn & med nas & & közénk & \\
\hline Ted & ob koga ob kaj & & ki mellé & mi mellé \\
\hline Ted & obme & & mellém & \\
\hline $\mathrm{Tdv}$ & ob naju & & & \\
\hline Tmn & ob nas & & mellénk & \\
\hline Red & okrog koga & okrog česa & ki köré & mi köré \\
\hline Red & okrog mene & & körém & \\
\hline $\mathrm{Rdv}$ & okrog naju & & & \\
\hline Rmn & okrog nas & & körénk & \\
\hline
\end{tabular}

\subsection{Krajevni skloni in skladi}

V pretežno krajevnem snopu prostih sklonov se pripone prav tako obračajo v predpone svojilne sprege, primerljive s predložnim mestnikom (Nartnik 1998/99: 81):

osebe stvari osebe stvari

$\begin{array}{lllll}\text { M ed } & \text { v kom } & \text { v čem } & \text { kiben } & \text { miben } \\ \text { M ed } & \text { v meni } & & \text { bennem } & \\ M d v & \text { v nama } & & \text { bennünk } & \\ M \text { mn } & \text { v nas } & & \text { kin } & \text { min } \\ \text { M ed } & \text { na kom } & \text { na čem } & \text { rajtam } & \\ M \text { ed } & \text { na meni } & & & \\ M d v & \text { na nama } & & \text { rajtunk } & \\ M \text { mn } & \text { na nas } & & \end{array}$


V priložnih skladih se izglasna pripadnost snopu še bolj jasno prenese na priloge, ki so tokrat sami primerljivi s predložnim orodnikom pa tudi mestnikom in rodilnikom:

\begin{tabular}{|c|c|c|c|c|}
\hline & osebe & stvari & osebe & stvari \\
\hline Oed & pred kom & pred čem & ki előtt & mi előtt \\
\hline Oed & pred mano & & előttem & \\
\hline Odv & pred nama & & & \\
\hline Omn & pred nami & & előttünk & \\
\hline Oed & nad kom & nad čem & ki fölött & mi fölött \\
\hline Oed & nad mano & & fölöttem & \\
\hline Odv & nad nama & & & \\
\hline Omn & nad nami & & fölöttünk & \\
\hline Oed & za kom & za čem & ki mögött & mi mögött \\
\hline Oed & za mano & & mögöttem & \\
\hline Odv & za nama & & & \\
\hline Omn & za nami & & mögöttünk & \\
\hline Oed & pod kom & pod čem & ki alatt & mi alatt \\
\hline Oed & pod mano & & alattam & \\
\hline Odv & pod nama & & & \\
\hline Omn & pod nami & & alattunk & \\
\hline Oed & med kom vse & med čem vse & kik között & mik között \\
\hline Oed & med mano in tabo & & közöttem és & \\
\hline Odv & med nama & & & \\
\hline Omn & med nami & & közöttünk & \\
\hline$M$ ed & ob kom & ob čem & ki mellett & mi mellett \\
\hline M ed & ob meni & & mellettem & \\
\hline $\mathrm{Mdv}$ & ob nama & & & \\
\hline $\mathrm{M} \mathrm{mn}$ & ob nas & & mellettünk & \\
\hline Red & okrog koga & okrog česa & ki körül & mi körül \\
\hline Red & okrog mene & & körülöttem & \\
\hline $\operatorname{Rdv}$ & okrog naju & & & \\
\hline Rmn & okrog nas & & körülöttünk & \\
\hline
\end{tabular}

Krajevnost sicer vključuje tudi priložno skladnost in sledenje:

$\begin{array}{lllll} & \text { osebe } & \text { stvari } & \text { osebe } & \text { stvari } \\ \text { M ed } & \text { po kom } & \text { po čem } & \text { ki szerint } & \text { mi szerint } \\ \text { M ed } & \text { po meni } & & \text { szerintem } & \\ \text { M dv } & \text { po nama } & & \text { szerintünk } & \\ M \text { mn } & \text { po nas } & & \text { ki után } & \text { mi után } \\ \text { M ed } & \text { po kom } & \text { po čem } & \text { utánam } & \\ \text { M ed } & \text { po meni } & & & \\ M d v & \text { po nama } & & \text { utánunk } & \\ M \text { mn } & \text { po nas } & & \end{array}$


- Odmik od krajevnosti $\mathrm{v}$ prosto iskanje in namen je primerljiv predvsem $\mathrm{z}$ 퍼 izpredložnim tožilnikom ednine, odmik v priložni neprid in vzrok ter nadomeščanje N pa s predložnim tožilnikom in rodilnikom:

Tmn

$>$ Ted

$\because \quad$ Ted

- Tdv

is Tmn

त Red

- Red

$\because \quad \mathrm{Rdv}$

Rmn

Red

Red

Rdv

Rmn

$$
\text { stvari }
$$

po kaj

po koga

pome

po naju

po nas

za koga

zame

za naju

za nas

zoper koga

zoper mene

zoper naju

zoper nas

zaradi koga

zaradi mene

zaradi naju

zaradi nas

namesto koga

namesto mene

namesto naju

namesto nas

za kaj osebe

stvari

kiért

értem

értünk

ki végett

végettem

végettünk

zoper kaj

ki ellen

ellenem

ellenünk

zaradi česa

ki miatt

miattam

miattunk

namesto česa

ki helyett

helyettem

helyettünk

\subsection{Startni skloni in skladi}

$\mathrm{V}$ pretežno startnem snopu prostih sklonov se pripone spet obračajo v predpone svojilne sprege, primerljive s predložnim rodilnikom (Tóth 1936: 11):

$\begin{array}{lllll} & \text { osebe } & \text { stvari } & \text { osebe } & \text { stvari } \\ \text { Red } & \text { iz koga } & \text { iz česa } & \text { kiből } & \text { miből } \\ \text { Red } & \text { iz mene } & & \text { belőlem } & \\ \text { Rdv } & \text { iz naju } & & \text { belölünk } & \\ \text { Rmn } & \text { iz nas } & \text { k šrosa } & \text { miről } \\ \text { Red } & \text { s koga } & \text { rólam } & \\ \text { Red } & \text { z mene } & & & \\ \text { Rdv } & \text { z naju } & & \text { rólunk } & \\ \text { Rmn } & \text { z nas } & & \end{array}$

V priložnih skladih se izglasna pripadnost snopu še bolj jasno prenese na priloge, ki so tokrat sami primerljivi s predložnim rodilnikom: 


\begin{tabular}{|c|c|c|c|c|c|}
\hline & osebe & stvari & osebe & stvari & $\because$ \\
\hline Red & izpred koga & izpred česa & ki elől & mi elöl & ㄱำ \\
\hline Red & izpred mene & & előlem & & $\dot{n}$ \\
\hline $\mathrm{Rdv}$ & izpred naju & & & & - \\
\hline $\mathrm{Rmn}$ & izpred nas & & elölünk & & $=$ \\
\hline Red & iznad koga & iznad česa & ki fölül & mi fölül & $\forall$ \\
\hline Red & iznad mene & & fölülem & & $\sim$ \\
\hline $\mathrm{Rdv}$ & iznad naju & & & & - \\
\hline $\mathrm{Rmn}$ & iznad nas & & fölülünk & & A \\
\hline Red & izza koga & izza česa & ki mögül & mi mögül & $\ll$ \\
\hline Red & izza mene & & mögülem & & $\mathbf{N}$ \\
\hline $\mathrm{Rdv}$ & izza naju & & & & - \\
\hline $\mathrm{Rmn}$ & izza nas & & mögülünk & & 7 \\
\hline Red & izpod koga & izpod česa & ki alól & mi alól & $\angle 1$ \\
\hline Red & izpod mene & & alólam & & 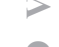 \\
\hline $\mathrm{Rdv}$ & izpod naju & & & & 0 \\
\hline Rmn & izpod nas & & alólunk & & $\neg$ \\
\hline Red & izmed koga vse & izmed česa vse & kik közül & mik közül & is \\
\hline Red & izmed mene in teb & & közülem és közülec & & 0 \\
\hline $\mathrm{Rdv}$ & izmed naju & & & & $\forall$ \\
\hline Rmn & izmed nas & & közülünk & & - \\
\hline Red & od koga & od česa & ki mellöl & mi mellől & $\mathbf{N}$ \\
\hline Red & od mene & & mellőlem & & 되 \\
\hline $\mathrm{Rdv}$ & od naju & & & & 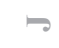 \\
\hline Rmn & od nas & & mellőlünk & & \\
\hline
\end{tabular}

\subsection{Dodatni skloni}

Skoz celo vrsto madžarskih primerov se je že pokazalo tudi pestrenje pregibanja v težnji po harmoniji samoglasnikov v okviru posameznih besed tipa ez - ezek nasproti az - azok ali kinek - nekem nasproti kiröl - rólam. Po pomenu pa prosti skloni kažejo predvsem na kraj kot cilj in start ter mero:

$\begin{array}{lllll} & \text { osebe } & \text { stvari } & \text { osebe } & \text { stvari } \\ \text { Ded } & \text { h komu } & \text { k čemu } & \text { kihez } & \text { mihez } \\ \text { Ded } & \text { k meni } & & \text { hozzám } & \\ \text { Ddv } & \text { k nama } & & \text { hozzánk } & \\ \text { Dmn } & \text { k nam } & & \text { kinél } & \text { minél } \\ \text { M ed } & \text { pri kom } & \text { pri čem } & \text { nálam } & \\ \text { M ed } & \text { pri meni } & & & \\ \text { M dv } & \text { pri nama } & & \text { nálunk } & \text { mitől } \\ \text { M mn } & \text { pri nas } & & \text { kitől } & \text { mitól } \\ \text { Red } & \text { od koga } & \text { od česa } & & \end{array}$


Red

$\mathrm{Rdv}$

Rmn

Red

Red

$\mathrm{Rdv}$

Rmn od mene

od naju

od nas

do koga

do mene

do naju

do nas tőlem

tőlünk

do česa

kihez

hozzámig

hozzánkig

Priložni skladi spet rajši vpenjajo daljšo pot $\mathrm{v}$ okvir ciljne ter startne smeri:

osebe

proti komu

proti meni

proti nama

proti nam

skoz koga

skozme

skoz naju

skoz nas

od koga

od mene

od naju

od nas stvari

proti čemu

osebe

ki felé

felém

felénk

skoz kaj

ki által

általam

általunk

ki felöl

felőlem

felőlünk

od česa stvari

mi felé

Rdv

Rmn

cod nas

Še drugačna je protistava prostega spremstva pa tudi rabe priložnemu nespremstvu pa tudi nerabi (Naumenko-Papp 1982: 251):

$\begin{array}{lllll} & \text { osebe } & \text { stvari } & \text { osebe } & \text { stvari } \\ \text { Oed } & \text { s kom } & \text { s čem } & \text { kivel } & \text { mivel } \\ \text { Oed } & \text { z mano } & & \text { velem } & \\ \text { Odv } & \text { z nama } & & \text { velünk } & \\ \text { Omn } & \text { z nami } & & \text { ki nélkül } & \text { mi nélkül } \\ \text { Red } & \text { brez koga } & \text { brez česa } & \text { nélkülem } & \\ \text { Red } & \text { brez mene } & & & \\ \text { Rdv } & \text { brez naju } & & \text { nélkülünk } & \\ \text { Rmn } & \text { brez nas } & & \end{array}$

Za razvoj v priloga sicer govori svojilna sprega prislovov recimo $\mathrm{h}$ krajevnemu snopu odvisnih sklonov kin - $\min$ (Šal'ga 1984: 90): 


\begin{tabular}{lllll}
\hline & osebe & stvari & osebe & stvari \\
Red & znotraj koga & znotraj česa & $\begin{array}{l}\text { kin belül } \\
\text { rajtam belül }\end{array}$ & min belül \\
Red & znotraj mene & & & \\
Rdv & znotraj naju & & rajtunk belül & \\
Rmn & znotraj nas & & kin kívül & min kívül \\
Red & zunaj koga & zunaj česa & rajtam kívül & \\
Red & zunaj mene & & rajtunk kívül & \\
Rdv & zunaj naju & & & \\
Rmn & zunaj nas & & &
\end{tabular}

\section{$5 \quad$ Povratni skladi}

Naposled je še pomenljivo, kako se snopi priložnih skladov s povratnoosebnim zaimkom nasproti predponsko-predložni sklanjatvi tega zaimka izjemoma ne obračajo v predpone (Mukič 1997: 236):

$\begin{array}{lll} & \text { osebe } & \text { osebe } \\ \text { Ted } & \text { podse } & \text { magam alá } \\ \text { Ted } & \text { podse } & \text { magad alá } \\ \text { Ted } & \text { podse } & \text { maga alá } \\ \text { Tmn } & \text { podse } & \text { magunk alá } \\ \text { Tmn } & \text { podse } & \text { magatok alá } \\ \text { Tmn } & \text { podse } & \text { maguk alá } \\ \text { Oed } & \text { pod sabo } & \text { magam alatt } \\ \text { Oed } & \text { pod sabo } & \text { magad alatt } \\ \text { Oed } & \text { pod sabo } & \text { maga alatt } \\ \text { Omn } & \text { pod sabo } & \text { magunk alatt } \\ \text { Omn } & \text { pod sabo } & \text { magatok alatt } \\ \text { Omn } & \text { pod sabo } & \text { maguk alatt } \\ \text { Red } & \text { izpod sebe } & \text { magam alól } \\ \text { Red } & \text { izpod sebe } & \text { magad alól } \\ \text { Red } & \text { izpod sebe } & \text { maga alól } \\ \text { Rmn } & \text { izpod sebe } & \text { magunk alól } \\ \text { Rmn } & \text { izpod sebe } & \text { magatok alól } \\ \text { Rmn } & \text { izpod sebe } & \text { maguk alól }\end{array}$

S slovensko sklanjatvijo se pri tem očitno prekrivata tako dana spregatev kakor štetje v snopih priložnih skladov. In zdi se, da ravno v zaporedju sprege, štetja in snopja tiči tudi razlaga za prekrivanje madžarskih končajev s svojilno sprego: 


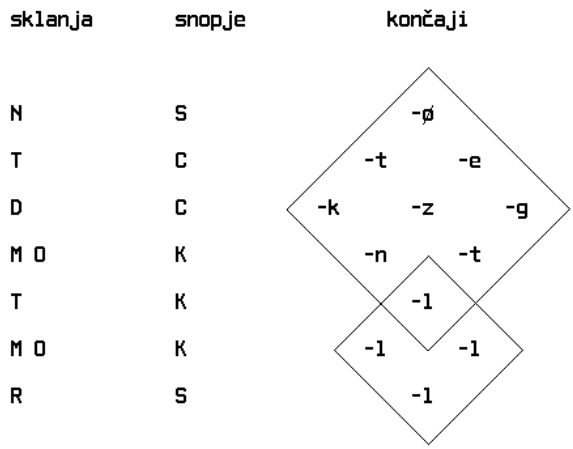

\section{Literatura}

Allières 2000 = Jacques Allières, Les langues de l'Europe, Paris: Presses Universitaires de France, 2000 (Que sais-je? 3559).

Bernjak 2004 = Elizabeta Bernjak, Slovenščina in madžarščina v stiku: sociolingvistične in kontrastivne študije, Maribor: Slavistično društvo Maribor, 2004 (Zora 29).

Bezlaj 2003 = France Bezlaj, Doneski k poznavanju glagolskega aspekta, v: France Bezlaj, Zbrani jezikoslovni spisi II, ur. Metka Furlan, Ljubljana: Založba ZRC, ZRC SAZU, 2003 (Linguistica et philologica 6/II), 693-712.

Deme 1984 = László Deme, A beszéd és a nyelv, Budapest: Tankönyvkiadó, 1984.

Erhart 1982 = Adolf Erhart, Indoevropské jazyky, Praha: Academia, 1982.

Kortlandt 2002 = Frederik Kortlandt, The Indo-Uralic verb, v: Finno-Ugrians and Indo-Europeans: linguistic and literary contacts, Maastricht: Shaker, 2002, 217-227.

Mukič 1997 = Francek Mukič, Slovenska slovnica, Szombathely: Zveza Slovencev na Madžarskem, 1997.

Nartnik 1982 = Vlado Nartnik, Modalni romb in modalne pretvorbe, Slavia 51 (1982), št. 3-4, 353-357.

Nartnik 1998/99 = Vlado Nartnik, Pregibanje spregalnoosebnih zaimkov pogovorne slovenščine med nemščino in italijanščino, Slava 12 (1998/99), št. 2, 77-82.

Nartnik 2006 = Vlado Nartnik, Prekrivnost slovenske in hrvaške sklanje samostalnih zaimkov, Riječ: časopis za slavensku filologiju (Rijeka) 12 (2006), št. 1, 90-102.

Naumenko-Papp 1982 = Agneš Naumenko-Papp, Praktičeskij kurs vengerskogo jazyka, Moskva: Vysšaja škola, 1982.

Skalička 1975 = Vladimír Skalička, K mad'arské gramatice, v: Lingvistické čitanky III: typologie 1, sestavil Bohumil Palek, Praha: Státní pedagogické nakladatelství, 1975, 5-48.

Šal'ga 1984 = Attila Šal'ga, Vengerskij jazyk v zerkale russkogo jazyka, Budapest: Tankönyvkiadó, 1984.

Tóth 1936 = Pál László Tóth, A mondatok grafikai ábrázolása (Mondattan), Budapest: Királyi Magyar Egyetemi Nyomda, 1936.

Tutek 2010 = Nikola Tutek, Kratka poredba osobnih, pokaznih i povratnih zamjenica i njihove sklonidbe u hrvatskom i mađarskom jeziku, v: Riječki filološki dani (Rijeka) 8 (2010), 729-739. 


\section{Similarities and differences between Slovenian and Hungarian inflection}

\section{Summary}

Slovenian and Hungarian are neighboring languages with very different inflection. They differ markedly in their verbal conjugation with regard to Slovenian imperfective versus perfective verbs, Hungarian differentiation in conjugation between the indefiniteness versus definiteness of the direct object in the accusative, Slovenian verbs of being and having, and Hungarian differentiation between the logical subject in the nominative or dative. Because Hungarian has no special form for the genitive, it has broadly developed the possessive inflection of substantival constructions of the type a szomszédok kandúrjuk (the neighbor-PL cat-POSS.PL) 'the neighbors' cat', rather than with a possessive suffix on the possessor. The Slovenian locative and instrumental cases each correspond to three sets each of simple cases and constructions with postpositions with a three-way orientational distinction. As part of three sets - allative, essive, and ablative - the simple case endings are turned into affixes on the possessive inflection, and in postpositional constructions a word-final suffix belonging to any of the three is transferred to the postposition. 